\title{
The Idea of Sustainability in European Union Energy Policy
}

\author{
Konrad Prandecki \\ Institute of Agricultural and Food Economics, National Research Institute, Warsaw, Poland \\ *Corresponding Author: kprand@interia.pl
}

Copyright $@ 2014$ Horizon Research Publishing All rights reserved.

\begin{abstract}
After many years of unsuccessful attempts the European Union common energy policy takes shape, indicating the targets for 2020 and even into mid-century. These actions occur at a fairly important time, because Europe's energy sector requires urgent changes resulting from the need to renew the capacity and transmission as well as to reduce the dependence on imported energy resources. The climate change is an additional challenge. It is important to assess the way in which the European policies intend to resolve these problems, respecting the principles of sustainable development. Indeed, the effective implementation of this concept in other areas of the economy will depend on its successful implementation in energy sector.
\end{abstract}

Keywords Sustainable Development, Sustainability; Energy Policy, European Union; Energy, Future Of Energy

\section{Introduction}

In recent years the European Union (EU) pursues its long planned mission to create a common energy policy more and more intensely. It is very important due to the significance of energy in the development of the European civilization. The shape of the new policy may be of fundamental importance for the EU, particularly on the implementation of the concept of sustainable development.

The energy policy should not only be regarded as an instrument of coordination between the member states, but also as an important contribution to the promotion of sustainable development. Firstly, this is due to the fundamental importance of this sector to the economy and people's lives. In addition, building the new policy from the beginning includes the possibility of comprehensive application of the theory of sustainable development, not just in selective gradually changing aspects.

In addition, it is worth noting that the sector covered by this policy has significant impact on all three basic orders of sustainable development, i.e. economic, social and environmental. It is therefore expected that the effective implementation of the policy will contribute significantly to the achievement of sustainable development in the European Union.

The aim of this article is to present the main actions undertaken recently by the European Union in the energy sector and to analyze them from the point of view of sustainability. Can the EU energy policy be considered sustainable? In the article there are also presented the European Union's long term energy strategies.

\section{EU Energy Policy - the Basic Assumptions}

The history of cooperation in the energy sector is permanently inscribed in the European integration. It is enough to mention the 1951 Treaty of Paris on the creation of the European Coal and Steel Community, which is regarded as the first manifestation of institutional cooperation in the framework of the current European Union, or the Messina Declaration of 1955. As the name suggests, the aim of the first of these documents was to introduce common rules for trade in coal, which was the primary energy source, particularly in the field of industrial production, in the 1950's. Gaining control over the movement of coal and steel production ensured reinforcing the supervision of European countries. However, despite many subsequent attempts to strengthen cooperation in the energy sector, European countries have failed to create a common policy in this area.

The attitude towards the cooperation in the field of energy has changed in the last few years. The first signs of change appeared in the 1990's. It is, however, the Green Paper of March 2006 that should be considered the first modern attempt to create a policy in this area. This document contained the first objectives of Community action in this sector [1]. Even the title of the document stresses that energy development should be based on the concept of sustainability. This is due to the application of the provisions of the Lisbon Strategy, particularly the Sustainable Development Strategy of the European Union, which requires the implementation 
of the concept of sustainable development into all sectorial policies.

The Green Paper emphasizes the six main areas of action. Worth mentioning among them are: the competitiveness, sustainable development and innovation in this sector. Actions, as outlined in this document, are intended to implement the three main objectives, namely: long term energy development, competitiveness and security of supply. They are to be carried out both internally and internationally [1].

These objectives have been confirmed in the January 2007 communication from the European Commission to the European Council and the European Parliament, entitled European Energy. This document proposed the creation of a Community energy policy. In addition to this, it set the strategic objectives to be achieved by 2050 , i.e. a reduction of CO2 emissions by $60-80 \%$ compared to the 1990 levels Policy [2]. This demand was also recorded in a different document/communication, published on the same day: Limiting global climate change to 2 degrees Celsius - The way ahead for 2020 and beyond [3]. Both documents discussed the same aims and objectives for the coming years, but the latter described in detail the challenges associated with climate change, justified the need for general counteraction, and showed the costs of action, and their omission. In both of these documents there were also included proposals for action on the reduction of $\mathrm{CO} 2$ emissions by 2020 , now commonly known as the climate and energy package.

The actions proposed by the European Energy Policy relate mainly to the internal energy market, and involve, among other things, the need to develop links between the countries and provide energy solidarity in the whole community. Moreover, emphasis was placed on the reduction of greenhouse gas emissions, and on aiding the development of new technologies, in particular in the use of renewable energy sources and increasing energy efficiency.

The European Energy Policy assumptions were not accepted undisputedly. The new members were afraid to introduce the restrictive regulations on the reduction of greenhouse gas emissions. What is more, at the meetings of the European Council they were only able to partially determine the objectives that have been included in the climate - energy package (December 2008). The assumptions of the package in short can be described as $3 \times 20$ :

- $20 \%$ increase in energy efficiency compared to projections for 2020 ,

- $20 \%$ reduction in greenhouse gas emission by 2020 , compared with the state in 1990 ,

- increasing the share of renewable energy sources (RES) in total primary energy consumption of the European Union to at least $20 \%$ by 2020 .

It is worth noting that the second of the above-mentioned objectives indicated the possibility of even a $30 \%$ reduction if other, non-EU, nations also become involved in acting against climate change. Despite the absence of such declaration from the other countries, many NGOs are trying to put pressure on the EU to fulfill this goal. In May 2010, the European Commission issued a Communication on the possibility of reducing the emission levels. It stated that, due to the lack of fulfillment of the conditions mentioned in the package, the change was not taken into consideration. The document also evaluated the costs of such an undertaking. This analysis took into account not only the financial aspects of a greater, $30 \%$ reduction, but also identified and assessed the likelihood of phenomena such as: carbon leakage, production restrictions, loss of competitive advantage compared to other regions of the world. According to the data, the cost of implementing further reductions of $\mathrm{CO} 2$ emissions would not be much greater than assumed in the original objectives of the package [4,5]. Apart from individual cases, such as the Chinese declaration on building a low carbon economy [6,7], few countries have taken initiatives to reduce emissions. However, in the framework of the EU action is taken to reach a $30 \%$ reduction. Some countries, including Poland, oppose this strongly. One of the most recent actions was aimed at the reduction of the amount of free of charge $\mathrm{CO}_{2}$ emission allowances. This idea was not accepted by the Central European Countries, and for this reason the European Commission is going to put more stress on the renewable energy sources [8].

In addition to this, it is worth noting that this requirement applies only to the sectors covered by the EU ETS. For other sectors, individual solutions are assumed, which can best be described as the need to reduce the emissions in the old Member States and the possibility of increasing them in the new Member States.

Furthermore, the minimum level of biofuel consumption in transport in 2020 was determined at $10 \%$ of total fuel use.

The adoption of the Lisbon Treaty in December 2007 (was an important event that) preceded the implementation of the package. Together with its entry into force, the provisions on energy were included in the EU primary law (Title XXI, art. 194 of the Treaty on the Functioning of the European Union). This text stresses the need to ensure the functioning of the energy market and the security of supply, as well as the need to promote energy efficiency and intra-relationships between countries [9]. This provision provides the basis for the creation of a common European energy policy. This does not mean, however, that such policy could not be earlier adopted. This involved only the use of the relevant provisions of the Treaty establishing the European Community, and in particular the parts regarding the services (Articles 49-55), the trans-European networks (Title XV, Art. 154-156) and the environment (Title XIX, Art. 174-176).

Climate and energy package, approved on 12 December 2008, until recently, has been regarded as the primary instrument of energy policy-making. In practice, this act is only a statement of the countries on the course of action, and the actual obligations are set in secondary legislation. Directives and decisions related to the package were adopted as early as 23 April 2009. This pace, quite extraordinary for an EU institution, demonstrates that the EU finds the energy 
and climate issues uniquely significant. It also provides a very rapid enforcement of the provisions, which were put in practice on 25 June 2009. As a result, member states had little time to adapt to the changes. The acts of the package include:

- Directive of the European Parliament and of the Council 2009/29/EC of 23 April 2009 amending Directive 2003/87/EC so as to improve and extend the greenhouse gas emission allowance trading scheme (the so-called EU ETS Directive),

- Directive of the European Parliament and of the Council 2009/31/EC of 23 April 2009 on the geological storage of carbon dioxide and amending Council Directive 85/337/EEC, European Parliament and Council Directives 2000/60/EC, 2001/80/ EC, 2004/35/EC, 2006/12/EC, 2008/1/EC and Regulation (EC) No 1013/2006 (the so-called CCS Directive),

- Directive of the European Parliament and of the Council 2009/28/EC of 23 April 2009 on the promotion of energy from renewable sources and amending and subsequently repealing Directives 2001/77/EC and 2003/30/EC (the Directive RES),

- The decision of the European Parliament and Council 2009/406/EC of 23 April 2009 on the effort of Member States to reduce their greenhouse gas emissions to meet the Community's 2020 commitments to reduce emissions of greenhouse gases (Decision non-ETS).

\section{Future of European Energy}

In March 2010, the European Commission presented a proposal for a new Community strategy for the next decade. This document replaced the Lisbon Strategy. The new solution, entitled Europe 2020. A strategy for smart, sustainable and inclusive growth, is now the most important development strategy of the European Union. It is based on three priorities defined as:

- "Smart growth: developing an economy based on knowledge and innovation,

- Sustainable growth: promoting a more resource-efficient, greener and more competitive economy,

- Inclusive growth: fostering a high-employment economy delivering social and territorial cohesion" $[10$, p. 5].

These objectives are to be achieved by means of seven projects:

a) "'Innovation Union" to improve framework conditions and access to finance for research and innovation so as to ensure that innovative ideas can be turned into products and services that support growth and job creation.

b) "Youth on the move" to enhance the performance of education systems and to facilitate the entry of young people to the labour market.

c) "A digital agenda for Europe" to speed up the roll-out of high-speed internet and reap the benefits of a digital single market for households and firms.

d) "Resource efficient Europe" to help decouple the economic growth from the use of resources, support the shift towards a low carbon economy, increase the use of renewable energy sources, modernise transport and promote energy efficiency.

e) "An industrial policy for the globalisation era" to improve the business environment, notably for SMEs, and to support the development of a strong and sustainable industrial base able to compete globally.

f) "An agenda for new skills and jobs" to modernise labour markets and empower people by developing their skills regardless of age, with a view to increase labour participation and to balance labour supply and demand, e.g. through labour mobility.

g) "European platform against poverty" to ensure social and territorial cohesion, so that the benefits of growth and jobs are widely shared and people experiencing poverty and social exclusion are enabled to live in dignity and take an active part in social life" $[10, p$. 5-6].

As can be seen from the list above, the problem of energy is mentioned only in one case, i.e. within The Resource Efficient Europe. This project is being implemented under the second priority purpose of sustainable development. The tasks scheduled in this area are limited primarily to fulfilling the $3 \times 20$ obligations of the energy and climate package. Furthermore the project was proposed in order to create a common energy market and to increase use of market-based instruments in this sector. An important novelty of this paper is highlighting the impact the transport sector has on energy consumption and greenhouse gas emissions and stressing the need for intensive efforts in this area. Another significant element of the strategy is to provide a vision for change in the energy sector by 2050 . Europe 2020 was adopted by the European Council in June 2010, becoming the official EU development strategy for the coming years.

The assumptions of the Europe 2020 strategy for the energy sector were described in a document entitled Energy 2020. A strategy for competitive, sustainable and secure energy [11], which was published on 10 November 2010. Its contents should be considered as a basic EU strategy for energy development, which contains both general and detailed information. The main aim of the document was to demonstrate the direction and tasks to be completed in the second decade of the twenty-first century.

It is very important that this text was written as part of a common EU energy policy, the basic principles of which were enshrined in the Treaty of Lisbon. The objectives for the next decade were preceded by an overall analysis of the situation in the European energy sector. It emphasized not only the advantages of the European systems (e.g. acquisition of $45 \%$ of electricity from low-carbon sources), 
but also the defects. These include outdated production capacity (up to 2020 about $1 / 3$ capacity for power generation should be replaced with new installations with approximately $30000 \mathrm{~km}$ of transmission lines to be replaced), limited consumer access to energy distributors, too tardy introduction of the projects related to the energy efficiency and the challenges connected with security of supply [11].

The above-mentioned document should be considered the most important Community strategy on energy. However, it only demonstrates the lines of action and areas of coordination of national policies, and does not prejudge the creation of a common policy.

Much more important decisions were made at the European Council meeting in February 2011, which, owing to the importance of energy, was the first meeting devoted mainly to this issue. In its conclusions of 4 February 2011, the leaders of the member states clearly announced that attempts shall be made to standardise the field of energy, especially to create a common energy market. The project should be completed by 2014 , before the implementation of the new financial perspective.

It is worth noting that the construction of the single market should be based on market mechanisms. The European Union intends also to take intensive measures to protect the poorest consumers against social exclusion which may result from the increase in energy prices. This item will be one of the main areas of periodic analysis of the market, presented by the European Commission [12].

The second of the major challenges awaiting the European Union is the intensification of energy security. The tasks will be implemented by means of several different strategies. Firstly, there is planned an integration of the national energy systems by increasing the connections between the Member States. The tasks in this area will concern mainly the construction of energy infrastructure, as well as the construction of primary energy transmission installations and the improvement of relations with third world countries. Secondly, intensified efforts will be made to increase internal capacity for energy production, by analyzing the possible use of fossil fuels (including shale gas) and renewable energy sources. Thirdly, an increase is assumed in the intensity of efforts to improve energy efficiency in the Community.

In the short term, these tasks are to be carried out mainly through the analysis of the current situation in the sector and through the creation of specific strategies. In this regard the EU plans, i.a.:

- the adoption of technical standards for smart grids and meters by the end of 2012 .

- including all member states into a common system of European gas and electricity networks by 2015 .

- the development of low-carbon development strategy up to 2050 by 2020 [12].

Significant interest in the development of the common energy policy raises hope that many of the goals could be achieved soon. The "new" member countries need a better security of supply. On the other hand, Western European countries intend to use it as a tool for implementing policies against climate change. In the West, however, one can observe a certain lack of understanding of the problems affecting the Central and South European countries, which renders many meetings ineffective. It should also be emphasized that it is important not only to develop specific strategies, but also to create the European law on this basis and to implement this law in the Member States.

The intensity of activities in the energy sector is also provided in the convention of the Council of the European Union on energy, on 28 February 2011, which mainly concerned the prioritization and delegation of the tasks resulting from the Europe 2020 document [13]. Furthermore, in March 2011, the first of the measures contained in the Council conclusions has been completed. In this context, the publication of a new plan for energy efficiency and the presentation of energy roadmap up to 2050 should be mentioned.

From the political point of view, the second of these documents bears more significance for the development of the European energy sector, as it determines the guidelines for almost forty years. Presented on 8th of March 2011, the plan to build a low-carbon economy by 2050 is a comprehensive document which shows that the European Union does not possess a long-term objective delimitation of energy development. The basic premise of this document is the development of the sector, leading to the reduction of greenhouse gas emissions by $80-95 \%$ by 2050 , compared with the 1990 levels [14]. This has been repeatedly mentioned already. Moreover, it is difficult to justify the repetition by a change of status of the document, because, as before, it is a non-binding announcement of action. A positive exception, which must be appreciated, is putting this code in a broader overall strategy of development of the sector, not just in the programs in the energy sector aimed at combating the climate change.

One should treat as a novelty the division of the process into stages. Apart from the planned initiatives provided for 2020, there are listed two intermediate objectives: achieving a $40 \%$ reduction by 2030 and $60 \%$ in 2040 . Nonetheless, they are not yet approved by member states. These activities shall be applied in all sectors of the economy, not just the selected ones, as it currently happens. It is difficult to find other particulars following the above-mentioned priorities. The activities planned for 2020 refer to existing documents, such as Energy 2020 and, therefore, are described precisely. In contrast to this, the directions of the initiatives undertaken in the subsequent stages are not so clear. Currently it is assumed that the investment in the energy sector will focus on three main areas: energy efficiency, decarbonisation and the development of renewable energy sources; but no standards have been set so far. It is clear that in the perspective of forty years, it is impossible to determine, with a high degree of probability, any tasks for economic policy, including the energy sector but certain assumptions have to be made. 
In December 2011, the European Commission presented another final long term strategy entitled Energy Roadmap 2050. This publication is dedicated to the actions which should be undertaken in order to achieve a low carbon economy. The scenarios lead to three main conclusions. In the long term, the energy sector will be shaped by: ecologization, electrification, and efficiency. These forces will have the strongest impact on the European economy [15].

In the energy sector forty years is not a very long time. Due to this, none of the scenarios predict that Europeans will use only renewable energy sources. In most cases, the key role is reserved for natural gas, which is predicted to become the main source of energy by 2050 . The differences between the scenarios consider the use of other resources. Such policy, based on diversification is called energy mix. The European Union does not want to push the Member States into any direction, that is why the use of a variety of sources is possible, but the consumption of those emitting more $\mathrm{CO} 2$ than gas will probably not be popular, due to the additional costs, such as the emission allowances. This situation limits greatly the development of the sectors based on these technologies, due to the difficulty of access to appropriate sources of funding. This is important i.a. for Poland, where such situation could mean unavailability of capital for investments in clean coal technologies. Even now one can observe the falling interest in using this strategic national resource.

Also surprising is the fact that the new energy roadmap almost completely ignores the issues of new technologies, the development of which will be of fundamental importance for the future of the sector. It is assumed, however, that all these shortcomings will be eliminated in the present decade. This means that the energy policy will be one of the major challenges of the European Union in the coming years. Its role is heavily affected by the financial crisis, but it is worth underlining, that energy issues are among the most often mentioned in the EU.

When describing the ongoing work on the construction of energy policy, it is necessary to refer to the strategy of energy efficiency of 8 March 2011. This document is a supplement to the previous studies in this area e.g. $[16,17]$, the objectives of which were considered not to be significant enough to be achieved by 2020 .

The problem of energy efficiency is an important challenge of the modern world. In the case of the growing energy demand, and the subsequent increase in its supply, it is difficult to explain the need to take action to rationalise the use of energy. However, this aspect of the energy policy of the European Union seems to be the most important element in the construction of sustainable development, because the reduction of demand can:

- increase the security of supply,

- reduce the dependence on the imported sources of primary energy,

- allow for more efficient management of resources,

- reduce the household maintenance costs,
- increase the competitiveness of enterprises,

- contribute to the reduction of greenhouse gas emission.

The current strategy of energy efficiency initiatives will be directed to the three main sectors: construction, transport and industry. Certain commitments have already been made in the first two sectors. These include such actions as forcing energy efficiency in public institutions to lower the energy costs $[18,19]$.

The actions planned for the next decade will require not only the use of new technologies, but also a change in the attitude towards energy use. For this reason there is also expected an increase in the employment opportunities for professionals in the field of energy efficiency, which will result in different training to support businesses and citizens in creating their own energy-saving programs [20].

\section{Sustainable Development and European Energy Policy}

The assumptions of the common energy policy are based on the concept of sustainable development. This information was repeated several times in the documents mentioned, which constitute the curriculum of the drawn policy. The reading shows, however, that it is mainly understood as a problem of climate change, particularly through the reduction of $\mathrm{CO} 2$ emissions. This postulate appears in virtually all contemporary documents relating to this sector. The objective pursued by the European Union in the gradual reduction of the greenhouse gases to a level no greater than $20 \%$ in 1990 , is laudable and has certainly helped to improve the quality of the environment. However, it is not accompanied by any specific attempt to determine what methods are to be used/what goals are to be achieved. This approach results in low reliability of the actions taken.

This applies to other strategic objectives, such as increasing energy efficiency. Previous efforts in this regard did not bring the expected results, which has led to some doubts about the possibility of achieving the objectives planned for 2020; especially if we take into consideration that four years have passed since the adoption of the climate and energy package.

The recent actions including the Energy Efficiency Plan form March 2011, have not been very effective either. The plan contains only general information, which means that only directives based on this law can become the basis for a thorough evaluation of the implementation of energy efficiency. Only the establishing of the European Energy Efficiency Fund on 1 July 2011 can be described as a success.

The activities that relate to the concept of sustainable development should also include promoting the development of renewable energy sources. In this regard, targets for 2020 have been clearly defined. It is difficult to determine the long term contribution of these sources of energy in the overall production. However, a number of international forecasts 
indicate that in 2050 renewables will not be a dominant source of energy. Even in Energy Roadmap 2050 natural gas is described as the main source of energy. In some cases renewables can play a significant role, but never the major one. We are facing a similar problem in the case of Carbon Capture and Storage technologies. It is expected that by 2025 the costs of installation and operation of such devices will be higher than the profits. In such case we should not expect enterprises to be interested in such investments.

The changes in the energy sector will come slowly. The fastest are expected to occur inbuilding markets, e.g. in the internalization of external costs (such as trading greenhouse gas emissions). The infrastructure, particularly the ability to produce energy, will be changing at a much slower rate, due to the long period of construction and installation operations. For this reason, it is expected that the power units that are currently under construction will be used until mid-century, with significant impact on the shape and position of the European member states' power. In terms of technology, it should be noted that the European Union's approach to the energy sector is not very balanced. The current standards developed in accordance with the rule of BAT, regard well-known technologies. However, it is highly probable that they will become outdated by 2030 . On the other hand, changes in energy occur slowly. It is not very likely that there will be invented new breakthrough technologies of mass energy production by 2030. According to P. Voser, Director of Royal Dutch Shell, it takes about 35 years to go from design to gaining $1 \%$ market share [21]. It is more likely that some innovation in already existing technologies, such as thermonuclear reactors, will be operating in the middle of the century. The commercial production of the fourth generation nuclear reactors is expected sooner, followed by the miniaturization of the technology as well as the use of more energy-efficient and economical equipment using renewable energy sources.

From the point of view of sustainability, the EU approach to the energy sector, should be evaluated negatively by far, because of the lack of interest in the social aspects and the production of energy in industry. Most of the regulations refer to the production of electricity or its transport. Few cases take the issue of heat into account, usually in the use of cogeneration technologies and energy efficiency. This way, the problems of households as well as those of many companies that need to generate heat for production are ignored. In some types of production processes heat is the most consumed type of energy [22]. In the case of the chemical industry, it often happens that the process of burning must come from a particular source (e.g. coal-based chemicals). Forcing companies to use drastic reduction of emission standards or to pay penalties, could cause a collapse of this sector of the economy. Lack of adequate solutions prepared on the EU level causes significant uncertainty and ill-considered regulation might instigate a reduction in investment in such sectors.

Another element, which from the point of view of sustainability, requires greater interest, is the recipient of the final energy. The changes carried out by the European Commission lead to an increase in energy prices, particularly in the price of electricity. This increase is difficult to predict for the time being. It is anticipated that in many countries (e.g. in Poland) there can be as much as $50-100 \%$ growth in electricity prices. Such a drastic change may become yet another reason for social exclusion. The problem of caring for the consumer, especially the poorest, appears in the published documents. However, it is difficult to find any specific solutions to facilitate the access to energy and to ensure the stability of its prices. In the latter case, we can analyze the issues of energy security, in particular as regards the relations with third world countries, which are the primary energy providers, but we cannot propose any mechanism to protect the client from the costs associated with the implementation of the principles of energy efficiency offered by companies and environmental technologies. This imperfection of the energy policy is the greatest limitation in the implementation of the concept of sustainable development.

Having analyzed past actions, it becomes clear that the European Union is moving towards the introduction of common rules in the field of energy. The basic premise, i.e. the support of sustainable development, despite many imperfections seems to be considered seriously. On the other hand, it is worth noting that the same rules do not change social attitudes and sometimes can even hinder the use of innovative solutions. It can be proved by the fact that there are no significant effects of the promotion of renewable energy sources. Despite the existence of many financial instruments within the EU it is always believed that the best place to invest in renewable energy is the U.S. and China, regardless of the fact that the two countries do not apply as sophisticated instruments to encourage the development of this type of energy as the EU.

\section{Conclusion}

The construction of a common EU energy policy is one of the priorities for the coming years. According to the Treaty on the Functioning of the European Union and the guidelines of the Europe 2020 strategy, the task should be carried out in accordance with the objectives of sustainable development. So far the priorities of this policy - security of energy supplies, increasing energy efficiency, reducing greenhouse gas emissions and promoting new manufacturing technologies (mainly renewable) - show that the European Community only formally intends to implement this concept.

Current initiatives are focused mainly on the issues of environmental sustainability. Moreover, a number of social activities, such as securing energy supplies and facilitating the flow of energy between two countries, are aimed in the macro dimension. It seems that from the perspective of sustainable development a new policy puts least attention to energy end-users, i.e. consumers and businesses. Such an approach can lead to a weakening of the competitive position 
of businesses and social exclusion of citizens.

Despite these shortcomings, a new Community policy should be seen as an important step towards the practical application of the concept of sustainable development.

\section{REFERENCES}

[1] Green Paper. A European Strategy for Sustainable, Competitive and Secure Energy", Commission of European Communities, Brussels, COM(2006) 105 final, 8.03.2006.

[2] An Energy Policy for Europe", Commission of European Communities, Brussels, Communication from Commission to The European Council and The European Parliament COM (2007) 1 final, 10.01.2007.

[3] Limiting global climate change to 2 degrees Celsius - The way ahead for 2020 and beyond", Commission of European Communities, Brussels, Communication from the Commission to the Council, the European Parliament, the European Economic and Social Committee and the Committee of the Regions COM (2007) 2 final, 10.01.2007.

[4] European Commission, Analysis of options beyond 20\% GHG emission reductions: Member State results”, European Commission, Brussels, Commission Staff Working Paper SWD(2012) 5 final, 1.2.2012.

[5] Analysis of options to move beyond 20\% greenhouse gas emission reductions and assessing the risk of carbon leakage", European Commission, Brussels, Communication from The Commission to The European Parliament, The Council, The European Economic and Social Committee and The Committee of The Regions COM(2010) 265 final, 26.5.2010.

[6] H. Shaowei, Challenges in building a low-carbon economy", China Daily, 7 January 2009.

[7] Xinhua, China to develop low-carbon economy", China Daily, 1 March 2010.

[8] European Economic and Social Committee, EESC in favour of a more integrated and cost-effective renewable energy strategy", European Economic and Social Committee, PRESS RELEASE No 81/2012, 17 December 2012.

[9] European Union, Consolidated Version of Treaty on Functioning of The European Union", Off. J. Eur. Union, nr C 83 , p. 47-199.

[10] Europe 2020. A strategy for smart, sustainable and inclusive growth", European Commission, Brussels, COM(2010) 2020 final, 3.03.2010.
[11] Energy 2020. A strategy for competitive, sustainable and secure energy", European Commission, Brussels, Communication from The Commission to The European Parliament, The Council, The European Economic and Social Committee and The Committee of The Regions COM(2010) 639 final, 10.11.2010.

[12] European Council, Conclusions from 4 February 2011", European Council, Brussels, EUCO 2/1/2011 REV 1, 2011.

[13] European Council, Council conclusions on Energy 2020: A Strategy for competitive, sustainable and secure energy", European Council, Brussels, 3072nd Transport Telecommunications and Energy (ENERGY) Council meeting Press: 35 PR CO 10 Nr: 6950/11, 28 February 2011.

[14] European Union, Climate change: Commission sets out Roadmap for building a competitive low-carbon Europe by 2050", European Union, Brussels/Strasbourg, IP/11/272, 8 March 2011.

[15] Energy Roadmap 2050", European Commission, Brussels, COM(2011) 885 final, 15.12.2011.

[16] Energy efficiency: delivering the 20\% target", European Commission, Brussels, Communicate from the Commission COM(2008) 772 final, 13.11.2008.

[17] Action Plan for Energy Efficiency: Realizing the Potential", European Commission, Brussels, Communicate from the Commission COM(2006) 545 final, 19.10.2006.

[18] European Union, Directive 2009/33/EC of The European Parliament and The Council of 23 April 2009 on the promotion of clean and energy-efficient road transport vehicles", Off. J. Eur. Union, nr L 120, p. 5-12.

[19] European Union, Directive 2010/31/EU of The European Parliament and of The Council of 19 May 2010 on the energy performance of buildings", Off. J. Eur. Union, nr L 153, p. $13-35$.

[20] European Commission, Commission Regulation (EU) No 109/2011 of 27 January 2011 implementing Regulation (EC) No 661/2009 of the European Parliament and of the Council as regards type-approval requirements for certain categories of motor vehicles and their trailers as regards spray suppression systems (Text with EEA relevance)", Off. J. Eur. Union, nr L 34, p. 2-28, 2011.

[21] P. Voser, Energy transition: not for the faint-hearted", The Globe and Mail, 17 September 2009.

[22] European Commission, Energy Efficiency Plan 2011", Brussels, Communication from The Commission to The European Parliament, The Council, The European Economic and Social Committee and The Committee of The Regions COM(2011) 109 final, 8.3.2011. 